\section{Field Experiment}

\section{Mike Brock and Natalia Borzino}

\author{
Mike Brock and Natalia Borzino
}

\title{
Using Incentives and Social Information to Promote Energy Conservation Behavior
}

\section{Contents}

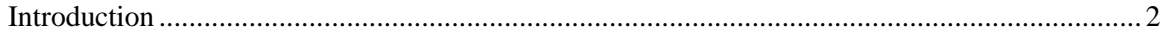

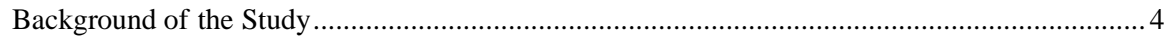

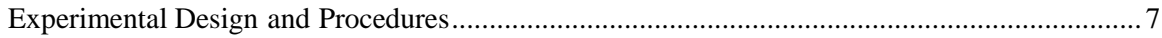

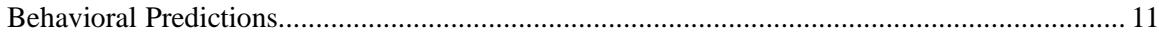

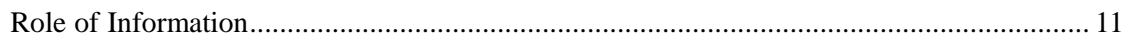

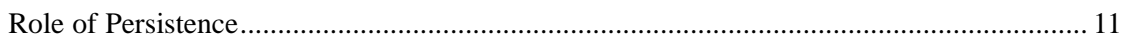

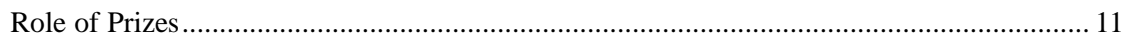

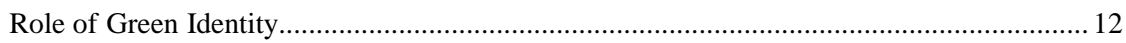

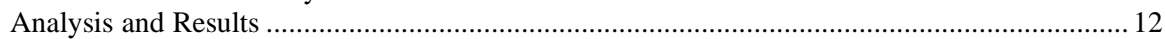

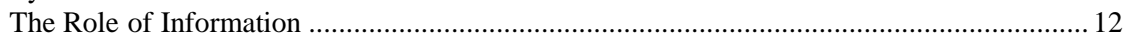

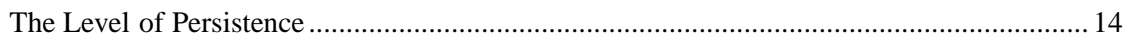

The Impact of Offering a Prize ..................................................................................... 16

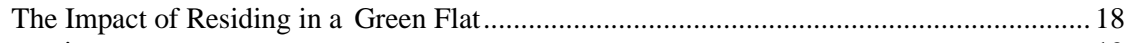

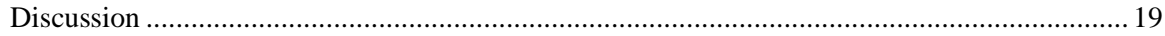

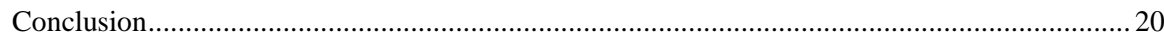

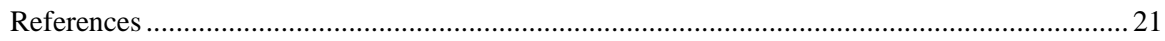

\section{Abstract}

Improving the efficiency in the domestic energy consumption has become a showpiece of how behavioral economics can be applied to the field of

All the authors conceived and designed the study. M.B. implemented the field study and data collection. N.B. performed the data management and analysis of the data. All the authors contributed toward the interpretation of the results and the writing of the manuscript.

M. Brock $(\approx)$

School of Economics, University of East Anglia, Norwich, UK

e-mail: michael.brock@uea.ac.uk

\section{N. Borzino}

Future Resilient Systems (FRS), Singapore ETH Centre, Singapore, Singapore e-mail: natalia.borzino@frs.ethz.ch 
environmental economics. This study builds upon the literature by providing subjects with individual and social energy performance information at group level in a controlled field experiment setting. We aim to test whether extrinsic incentives accentuate or crowd out the intrinsic motivation to save energy and how heterogeneity in environmental attitudes also impacts on electricity conservation. Besides, we test for the persistence of energy-saving habits after the information is removed. Results suggest that the provision of individual feedback and social information increase energy conserving behavior, with this being most effective among those who signaled in a previous stage preferences for pro-environmental and sustainable living. However, treatment variations indicate that subjects overall fail to maintain "good habits" once the intervention stops, with exception of pro-environmental subjects who continue to consume less electricity in the post-intervention phase. Furthermore, our findings indicate that rewarding groups in a competitive environment may create perverse long-run effects. While providing individual and social information could improve both consumer welfare and energy demand forecasting, the timescale, frequency, and mechanism undertaken require careful scrutiny and planning if these potential benefits are to be maximized and undesirable side effects prevented.

Keywords

Behavioral nudging - Social norms · Extrinsic motivation · Field experiment · Group coordination $\cdot$ Sustainability $\cdot$ Environmental economics

\section{JEL Classifications}

Q4 $\cdot \mathrm{Q} 56 \cdot \mathrm{H} 31 \cdot \mathrm{L} 94$

\section{Introduction}

Improving the efficiency of domestic energy consumption has become a showpiece of how behavioral economics can be applied to the field of environmental economics. The use of behavioral "nudges," which are non-price interventions grounded in psychology and behavioral economics, has been proven to be an effective tool that improves consumption awareness and instill positive environmental habits (Allcott 2011; Kunreuther and Weber 2014).

Student residences in a UK university campus could be a good setting for assessing the effectiveness of such nudging. One reason is that students are relatively unfamiliar with understanding their patterns of energy usage as compared with the average population; hence, they are more receptive to behavioral adaptation. Moreover, the rent of student residences is typically predefined and inclusive of utility bills. This means that throughout the study trial, no financial advantages are made (by the participant) if the students become more energy-efficient. It could be assumed that any behavioral change stems from an intrinsically motivated response to the imposed treatment. 

103 in the field. savings.

In our experimental study, we nudge students to be more energy-efficient by providing them with information about their electricity consumption. Specifically, students were informed of their absolute (i.e., individual information) and relative to others' (i.e., social information) energy usage via a weekly email between January and May 2017. The study explores whether (a) individual feedback and social information creates a fall in consumption per se, (b) conservation behavior persists once the information stimulus is removed, and (c) the introduction of an extrinsic motivation in a form of rewards heightens or offsets the desire to make energy

Our results imply, and in line with relevant literature, that a small (4-8 percentage points) yet significant reductions can arise when subjects are provided with individual and social comparative energy consumption information. In fact, treated students exhibited a decrease in their energy consumption from an above-average consumption to a below-average one relative to their building-level cohort. When exploring the second and third research questions, the study identifies some novel insights which are potentially useful from both a social and policy-based standpoint. Regarding the persistence of conservation behavior, it seems that most subjects quickly lose any "good habits" (and return to pretreatment levels of energy consumption) once the email intervention ceases and the information stimuli are removed. Interestingly, this pattern is not seen among students who self-signaled as environmentally friendly in a previous stage prior to this study. They not only decrease their consumption during the intervention period but also continue to exhibit lower levels of energy usage in the post-intervention period. Regarding extrinsic motives, the added incentive to win a prize appears to accentuate energy conservation behavior. However, once the prize allocations are determined, these conservation habits come to a halt, and subjects within this sub-treatment group exhibit significantly higher energy usage in the post-intervention phase.

These findings therefore issue a mixed message for the energy policy field. On the one hand, the results show that providing individual and social information can constitute an effective environmental nudge and lead to efficiency gains. However, the time frame and type of mechanism employed require careful planning if one is seeking to optimize societal benefits and indeed if unwanted (or inefficient) consumption patterns are to be avoided in the long run.

The rest of the paper is structured as follows: Section "Background of the Study" outlines the literature on environmental nudging in the energy sector; Section "Experimental Design and Procedures" describes the study experimental design and procedures; Section "Behavioural Predictions" presents the behavioral predictions; Section "Analysis and Results" provides the results and associated data analyses; Section "Discussion" proceeds with some further discussion; and section "Conclusion" concludes and recommends some future steps for research and policy 


\section{Background of the Study}

Research has shown that people on suboptimal energy tariffs are not persuaded to act even when provided with information on the possible financial savings they could make by switching to a more convenient deal offered by the same or another service provider (Giulietti et al. 2005). Domestic energy constitutes around 27\% of the UK's demand for fuel (DECC 2015), wherein associated savings derived from the improved awareness on energy consumption could be substantial both for individuals and at aggregate levels. Research also indicates that many people overconsume energy and the only dissemination of the advantages of energy efficiency rarely results in any significant behavioral adaptation. False perceptions play a major role here, where users could hold untrue or incorrect weighted ideas on the relative energy requirements of domestic appliances (Attari et al. 2010; Allcott 2011a). The impact of this is that individuals often undertake "energy-saving behavior" that creates financial savings that fall short of their expectations (HM Government 2006). Undoubtedly, the introduction of personal energy usage interfaces and the associated move to make these freely available (www.smartenergygb.org) could combat this effect. However, it is important to highlight that uptake is voluntary and thus the likelihood of a self-stimulated action is projected to be less extensive in consumer areas where widespread disengagement exists.

The combination of effects mentioned above, which contributes to the deterioration of energy conservation, has created an intense research field seeking to establish whether behavioral economics and psychology can successfully address people's unwillingness to act (Abrahamse et al. 2005; Allcott and Mullainathan 2010; Croson and Treich 2014). The studies also assess the relative success of using alternative tools to engage consumers in a more pro-environmental behavior.

In this sense, "nudges" (Thaler and Sunstein 2009) have been shown to be a successful tool to influence decision-making in diverse settings, including the energy sector (see, for example, Abrahamse et al. 2005; Allcott and Mullainathan 2010; and Croson and Treich 2014). A leading mechanism used by behavioral economists is to test the role of social comparisons (Bault et al. 2008; Allcott 2011b; Czajkowski et al. 2014; Dasgupta et al. 2016). The associated theory is that people tend to react oversensitively to their performance or status relative to their peers. Thus, explicitly showing individuals how they perform in comparison to their peers could increase levels of energy efficiency leading to reductions in consumption and improving of their energy standing. These social comparisons have been implemented in many ways. Popular techniques have fused percentile statistics with a diagrammatic trigger, for example, a happy or sad face (Allcott 2011b) or "green stars" (Costa and Kahn 2013). The belief is that the latter element reinforces comparative performance. Other studies provide an explicit ranking breakdown, which illustrate precisely where a subject lies in relation to their peers (Delmas and Lessem 2014; Alberts et al. 2016). The results from these studies are encouraging, implying energy consumption can fall by a magnitude between 0 and 10 percentage points (Allcott 2011b; Delmas and Lessem 2014). 

164 2014; Alberts et al. 2016). 165 A difficult aspect within this type of research is to unravel the motives that drive
166 an individual's behavioral change. This is particularly tasking because energy 192 incentives exist.

Gains from nudging have been even greater in other areas of environmental economics, including the promotion of recycling and reduction of food wastage (Convery et al. 2007; Kallbekken and Sælen 2013).

Studies have typically believed that the greatest reductions arise from the initially poor performers, although counterarguments have also been reported in recent studies. Indeed, social comparisons may create a "discouragement effect" which disincentivizes weaker participants (Hargreaves et al. 2013; Alberts et al. 2016) under certain conditions. On the other hand, Delmas and Lessem (2014) concluded from their study that alongside incentivizing the worst performers, relative information also heightens the efficiency of already high performers. They attribute this to such respondents wanting to maintain a high status. This in turn defies the "Jevons paradox" (Alcott 2005), which would predict that as one is identified as a relatively strong performer, one should react by raising their energy consumption. This heterogeneity implies that "targeted" dissemination (regarding both how the information is presented and to whom) could be crucial when seeking to ensure environmental gains can be made from such an intervention (Allcott and Rogers efficiency provides a "win-win" situation for the environment and the agents given that, by decreasing their electricity consumption, it also produces (at times substantial) financial private gains (Kallbekken and Sælen 2013). Consequently, energy conservation contains attributes akin to an impure public good (see, for example, Kotchen 2009), and so disentangling the effects produced by the stimuli, and determining the incentives that influence decision-making, is a tall order.

Using student accommodation in a controlled field experiment does partially alleviate this problem (Delmas and Lessem 2014; Alberts et al. 2016) as most university residences offer rental contracts that are inclusive of utility bills. Moreover, prices are set prior to residency and remain fixed throughout tenancy, which eliminates any financial advantages to students in relations to the amount of energy they consume. Thus, if adjustments in energy usage are witnessed once subjects are provided with performance information, this gives a clearer indication that actions are driven by an intrinsic desire to improve their standing or to act pro-socially. In this respect, the study setting is "cleaner." Furthermore, there is evidence that in this context, subjects are typically more receptive to behavioral adaptation (Giuliano and Spilimbergo 2009). This is one of the reasons why some experimenters believe student cohorts are less representative of the wider population although some existing studies prove otherwise (Druckman and Kam 2009). Nonetheless, we apply an air of caution regarding the extent to which any findings could be fully applicable to a wider population. This is one motive for offering a subset of students the opportunity to win a prize in this study. By doing so, their consumption levels are compared with others within the trial to further explore the motivational conundrum exhibited by students. We could also potentially provide findings that may be applicable to the domestic residential market where both intrinsic and extrinsic 

211 change. 218 ple Urdiales et al. 2016). 227 trajectory across the study period.

This project also builds upon the existing literature in other domains. The first is that information is provided to groups of respondents who share a living space (hereon in referred to as "flats"). Findings from both laboratory and field experiments indicate that groups exhibit stronger tendencies for pro-social action than when people act as individuals (Mancur Olson 1965; Fehr and Schmidt 1999; Frank 2003). This pattern is observed across public good games, voluntary actions, waste reduction, and environmental affiliation. The notion is also supported by the subjective well-being literature, stating that "interconnectivity" and feeling part of something bigger than oneself instill a stronger societal construct and level of psychological happiness (Putnam and Alone 1995; Diener and Biswas-Diener 2011). This in turn facilitates instances of altruism (Andreoni 1990), reciprocity (Sugden 1984), or positive social action (Czajkowski et al. 2014). Alternatively, it could be argued that groups could bring about greater energy conservation through the competitive atmosphere it imposes. Indeed, when presented as a "team," respondents frequently react more fiercely in order to improve their standing relative to rival groups (Terry et al. 1999; Baik 2008; Konrad 2009; Nitzan and Ueda 2009). Regardless of the disposition that motivates them, disseminating information to a group seeks to understand if (and to what extent) this adjusts the scale of behavioral

In this study, we also attempts to understand whether and how those who indicated to be committed to an environment of sustainable living react to comparative information. Therefore, we seek to explore to which extent self-reported positive environmental attitudes are also reflected in actual energy-efficient performance. Past literature shows evidence of a positive relationship between selfreported pro-environmental habits and concrete eco-efficient actions (see forexam-

To test this, we analyze the behavior of a subset of our treatment flats, which are part of a long-standing movement at the university, known as "The Green Flats Project." These students, when completing their accommodation application form, indicated their preference to reside with other people that share the same pro-environmental attitudes and also wish to live in a sustainable way. Including this treatment affords the chance to study whether "Green Flat" residents (i) hold "below-average" baseline usage prior to information dissemination, (ii) are more or less responsive to the comparison data, and (iii) display a different consumption

We also want to study how extrinsic motivations could affect the behavior of participants. To analyze this, around half of the treatment flats enter into a competition for prizes, with the winners being those flats who consume the least energy per student during the intervention period. The literature here suggests two possible impacts from implementing this treatment. On one hand, contests typically create incentives for an overprovision of effort relative to the socially optimal level. Such "over-dissipation" (Konrad 2009) is accentuated in experimental settings, where the extent to which respondents engage in the contest consistently exceeds the thresholds predicted by theory (Davis and Reilly 1998). This is exacerbated in instances where prizes are distributed proportionally (Cason et al. 2010), or when the prize 

248 relevant to consider. 258 in that way, they get reinforced their self-image and status (Cerasoli et al. 2014).

quality is high (Doraszelski and Markovich 2007), there is a heightened "desire to win" (Lugovskyy et al. 2010) and when we see a greater degree of homogeneity among contestants (Clark and Riis 1998; Baik 2008). In contrary, opposing literature shows empirical and experimental examples (Bergstrom et al. 1986; Pellerano et al. 2017) where such extrinsic incentives offset (or "crowd out") the innate or intrinsic motive to act in a pro-social way. Based on this crowding-out literature, it is suggested that paying people for an activity may help in the short run but reduce their intrinsic motivation to perform the task in the long run once the incentives are removed. An overview of the evidence surrounding this area is provided by Cerasoli et al. (2014), and it is certainly an aspect that is both interesting and highly policy-

Finally, there is often disagreement in this research domain as to how persistent habits are once a "nudge" is removed. For associated policy, understanding the longterm benefits of an intervention is crucial for forecasting the impact(s) and estimating the financial outlay required in order to achieve a successful outcome. Existing evidence in this domain varies, with some studies suggesting that behavioral habits can partially persist into medium to long term (Abrahamse et al. 2005; Allcott and Rogers 2014), while others indicate that pro-social actions quickly dissipates once the intervention disappears (Dolan and Metcalfe 2013). Intrinsically motivated 259 To test this, we stop sending emails to a subset of our student groups halfway 260 through the trial period. Half of those subset of students were part of the "Green Flats 261 Project," while the other half were not. By comparing their consumption against 262 those who obtain the ranking email for the whole intervention time frame, the 263 question on habit persistence can be further explored.

264 By imposing these new elements onto an existing research framework, this study 265 looks not only to confirm and reinforce some of the current beliefs on how non266 financial stimuli can incentivize behavioral change but also to examine how such an 267 action might be influenced by facets of persistence, extrinsic motivation, and prior 268 attitudes toward sustainability.

\section{${ }_{269}$ Experimental Design and Procedures}

270 The experiment ran between January and May 2017 at the University of East Anglia 271 (UEA), Norwich, UK. Fourteen flats were selected for the study that involved 272140 students. An overview of the flats and their attributes is given in Table 1. Before 273 the trial began, participants were informed that the energy they used in residences 274 would be logged and that this (anonymized) data would be sent to them through a 275 weekly email. This would show their absolute usage and how this is compared to the 276 other residences which partook in the study. It was made explicitly clear that relative 277 efficiency would not lead to a change in accommodation fees. signaled a preexisting preference for a pro-environmental lifestyle deviated from the 
Table 1 The monitored flats and their characteristics

\begin{tabular}{|c|c|c|c|c|}
\hline Flat name & Number of students & Email stopped after 6 weeks & Green & Prize \\
\hline AA17 & 12 & & & $\checkmark$ \\
\hline BB17 & 8 & $\checkmark$ & $\checkmark$ & \\
\hline $\mathrm{CC} 17$ & 10 & & & $\checkmark$ \\
\hline DD17 & 10 & & & $\checkmark$ \\
\hline EE17 & 10 & $\checkmark$ & & \\
\hline FF17 & 10 & $\checkmark$ & & \\
\hline GG17 & 10 & & $\checkmark$ & $\checkmark$ \\
\hline HH17 & 10 & & & $\checkmark$ \\
\hline II17 & 11 & & $\checkmark$ & $\checkmark$ \\
\hline JJ17 & 11 & $\checkmark$ & $\checkmark$ & \\
\hline KK17 & 11 & & & \\
\hline LL17 & 9 & & & $\checkmark$ \\
\hline MM17 & 9 & & & $\checkmark$ \\
\hline NN17 & 9 & & & \\
\hline
\end{tabular}
284 ity when they live in the flat through the academic year.

285 In order to test the role of persistence, four of the flats in the study would (without 295 week 8 of the timeline given in Table 2 .

296 When exploring the role of the extrinsic motivation, the selection of the prize had 297 to be chosen carefully. Instead of offering direct monetary incentives, the prizes 303 perceived as something that students would value with greater equity than monetary 304 equivalents given the diversity in the students' financial backgrounds.

main cohort. Possible differences could be anticipated in relation to the general (base) usage or how individuals and comparative information influenced energy performance. While the "Green Flats Project" has existed at the UEA for a number of warning) stop receiving the emails, yet their usage continued to be logged and ranked. The monitoring of energy usage also continued beyond the information dissemination period for all flats, in what is later described in the results and discussion sections as the "post-intervention" time frame. Table 2 shows that following 10 weeks of emails, the Spring Semester was bisected with 4 weeks of an Easter break. Students returned, and for a period of 6 weeks, the monitoring continued. However, email communications stopped after 4 of these weeks, affording a chance to see if (short-run) habits persisted in the absence of a reminder for the remaining ten flats. For the four flats mentioned above, emails stopped in students were competing for including (i) a three-course meal and drinks at one of the on-campus restaurants and (ii) lunch vouchers for the same establishment. These prizes present positive advantages. Firstly, given that readings were taken at group level, it reinforced an idea of cohesion within flats, which brings about the notion of working as a team and being rewarded in the same way. Secondly, this prize was 5 Each flat was fitted with a monitor that isolated, logged, and stored energy usage data. Meter readings were taken at the same time of each week, and students were 
Table 2 Timeline of the study \begin{tabular}{l|l|l|l|l|l|l|l|l|l}
\hline 1 & 2 & 3 & 4 & 5 & 6 & 7 & 8 & 9 & 10 \\
\hline
\end{tabular} \begin{tabular}{|l|l|}
11 & 12 \\
\hline
\end{tabular} \begin{tabular}{|l|l|l|l|}
13 & 14 & 15 & 16
\end{tabular} 17 18 19 20 21 22 \begin{tabular}{|l|l|l}
\hline Easter (emails not sent) & Semester Part 2 (email sent) & Posttreatment (emails not sent) \\
\hline
\end{tabular} 


\section{Energy Monitoring Research Project}

Week

8

Your Flat Code DD17

This Week

\begin{tabular}{|l|l|l|}
\hline Rank & \multicolumn{1}{|c|}{ Team } & \multicolumn{1}{|c|}{ Usage } \\
\hline 1 & BB17 & 10.56 \\
\hline 2 & NN17 & 11.16 \\
\hline 3 & HH17 & 15.49 \\
\hline 4 & KK17 & 15.55 \\
\hline 5 & GG17 & 16.97 \\
\hline 6 & MM17 & 18.00 \\
\hline 7 & CC17 & 18.44 \\
\hline 8 & EE17 & 18.78 \\
\hline 9 & LL17 & 19.93 \\
\hline 10 & FF17 & 21.94 \\
\hline 11 & DD17 & 22.31 \\
\hline 12 & II17 & 23.55 \\
\hline 13 & JJ17 & 25.55 \\
\hline 14 & AA17 & 26.81 \\
\hline & &
\end{tabular}

\begin{tabular}{|l|l|r|}
\hline Rank & Team & \multicolumn{1}{|c|}{ Usage } \\
\hline 1 & BB17 & 917.63 \\
\hline 2 & HH17 & 1182.96 \\
\hline 3 & MM17 & 1236.00 \\
\hline 4 & NN17 & 1300.90 \\
\hline 5 & GG17 & 1306.33 \\
\hline 6 & KK17 & 1351.52 \\
\hline 7 & EE17 & 1472.60 \\
\hline 8 & CC17 & 1598.00 \\
\hline 9 & DD17 & 1720.00 \\
\hline 10 & LL17 & 1761.65 \\
\hline 11 & FF17 & 1764.80 \\
\hline 12 & AA17 & 2374.04 \\
\hline 13 & II17 & 2402.80 \\
\hline 14 & JJ17 & 2432.79 \\
\hline
\end{tabular}

\begin{tabular}{|l|l|}
\hline \multicolumn{1}{|c|}{ Week } & \multicolumn{1}{c|}{ Rank } \\
\hline 1 & $7^{\text {th }}$ \\
\hline 2 & $9^{\text {th }}$ \\
\hline 3 & $11^{\text {th }}$ \\
\hline 4 & $9^{\text {th }}$ \\
\hline 5 & $11^{\text {th }}$ \\
\hline 6 & $11^{\text {th }}$ \\
\hline 7 & $7^{\text {th }}$ \\
\hline 8 & $11^{\text {th }}$ \\
\hline 9 & \\
\hline 10 & \\
\hline 11 & \\
\hline 12 & \\
\hline 13 & \\
\hline 14 & \\
\hline
\end{tabular}

To opt out at any time, email michael.brock@uea.ac.uk

Fig. 1 A sample email

307 emailed on the following day of each week. Figure 1 shows that information was 308 disseminated to students through three tables. One showed weekly usage and the 309 associated rankings across all competing groups. A second gave the same informa310 tion for overall usage and ranking since the beginning of the intervention period. The 311 final table provided a "ranking timeline" for the course of the trial period. 


\section{${ }_{12}$ Behavioral Predictions} 319 removed. Furthermore, we aim to study whether and in which extent extrinsic 320 incentives have an effect on energy conservation. Lastly, we want to analyze whether 321 subjects who self-signaled to have a pro-conservation or "green" identity respond in 322 a greater magnitude to the information compared to those who did not identify 323 themselves as being environmentally friendly.

\section{Role of Information}

\section{H1: Students receiving individual and comparative feedback increase energy 326 conservation.}

327 This hypothesis is built on the notion that receiving both individual and social 328 information in the form of a league table will stimulate efforts to lower per-student 329 usage over time. This is grounded in the notion that the league table incites 330 competitive tendencies and a desire for flats to improve their relative standing in 331 the league.

\section{${ }_{332}$ Role of Persistence}

3 3з H2: Those who stop receiving feedbacks increase their electricity consumption as 334 compared with those who keep receiving information.

335 This second hypothesis follows the notion that the students in flats where the 336 email stopped halfway through the trial are likely to have a higher energy usage than 337 those who continue to receive emails. At the very least, we would expect the former 338 group to be returning to prior intervention levels as they revert to their original habits 339 in the absence of individual and social energy information. This provides one 340 measure of persistence.

\section{${ }_{341}$ Role of Prizes}

342 H3a: The existence of extrinsic incentives will increase conservation efforts. ${ }_{343} \mathrm{H3b}$ : Once the rewards are given, subjects return to the pretrial level of 344 consumption.

345 This is the conjecture that extrinsic rewards stimulate respondents in the "prize" 346 treatment to reduce energy usage to a greater extent. A related hypothesis is that this 

353 removed.

\section{${ }_{354}$ Role of Green Identity}

355 H4a: Self-signaled pro-environmentally friendly individuals react stronger to the 356 feedbacks by reducing the electricity consumption more than the nonself-identified 357 "green" subjects.

$358 \mathrm{H} 4 \mathrm{~b}$ : Self-signaled pro-environmentally friendly individuals persist in their conser359 vation habits after the feedbacks are removed.

360 The first hypothesis revolves around the idea that students who have expressed 361 prior preferences to act sustainably will have a lower energy usage on average as 362 compared to those who have not made this commitment. If this effect is accentuated 363 by reputation, we would also expect the gap between these two groups to widen 364 overtime during the intervention period. Furthermore, we expect these subjects to maintain their good habits even after the information is removed. Indeed, once individuals experience the positive aspects of being more energy-efficient, their positive self-image and status improve reinforcing their intrinsic motivation for behaving pro-environmentally. This will further encourage them to maintain their 369 conservation habits even after the intervention period is over.

\section{${ }_{370}$ Analysis and Results}

371 In this section, we are presenting the results from our analysis over aggregate and 372 heterogeneous behaviors using uniquely generated experimental data. Our research 373 questions are addressed in the subsections below, and accordingly, we assess 374 whether our results validate or reject our behavioral predictions.

\section{${ }_{375}$ The Role of Information}

One of the major aims of this research was to identify whether the provision of energy information impacted upon subsequent behavior. In order to assess this usage against that of those students not in the study, the University Estates Division was able to provide aggregated monthly energy usage for the associated residential buildings covering the study period. These buildings comprise entirely of student accommodation, meaning the two data-sets are comparable across the experiment's 
Table 3 A comparison of flat usage against the building baseline

\begin{tabular}{cl|l|l|l|r}
\cline { 3 - 6 } & & $\begin{array}{l}\text { Average weekly } \\
\text { usage [building } \\
(\text { KwH)] }\end{array}$ & $\begin{array}{l}\text { Average weekly usage } \\
\text { [study flats (KwH)] }\end{array}$ & $\begin{array}{l}\text { Difference } \\
(\%)\end{array}$ & t-statistic $(p)$ \\
\cline { 3 - 7 } t:2 & January & 19.65 & 20.47 & $+4.14^{* *}$ & $2.43(0.01)$ \\
\cline { 2 - 6 } t:3 & February & 20.38 & 20.93 & $+2.69^{*}$ & $1.63(0.051)$ \\
\cline { 2 - 6 } t:4 & March & 16.07 & 15.74 & $-2.03^{*}$ & $-1.3(0.09)$ \\
\cline { 2 - 6 } t:6 & April & 12.75 & 12.55 & +1.64 & $-0.079(0.21)$ \\
t:7 & ${ }^{*} p<0.1,{ }^{* *} p<0.05$ & 13.99 & 14.36 & $+2.64^{*}$ & $1.47(0.07)$ \\
\hline
\end{tabular}

Comparing Treatmeant Flats against Average Buildings Usage

$(\mathrm{KwH})$

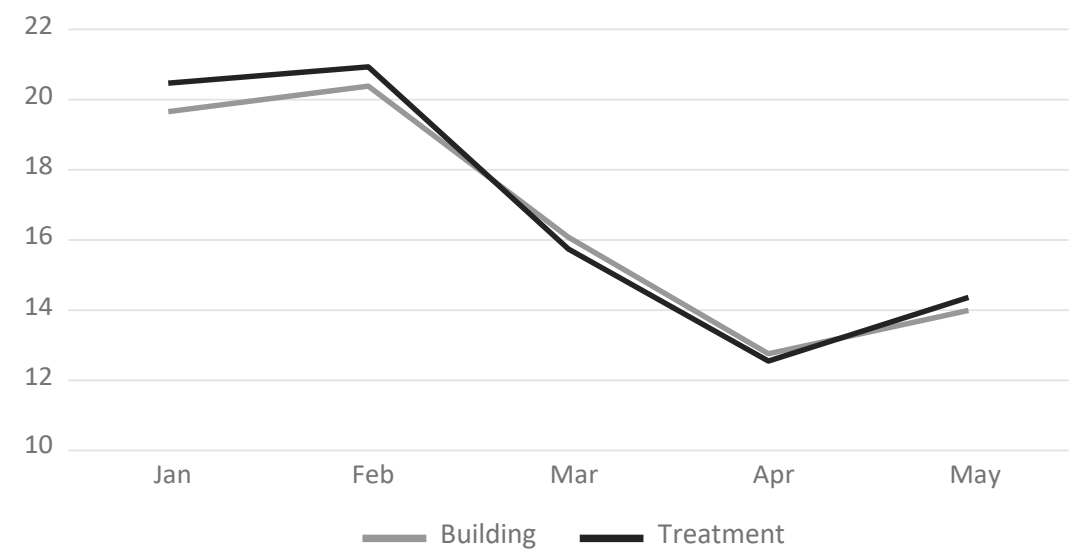

Fig. 2 Comparing treatment flat and building usages

382 time frame. The results identify a clear pattern of energy conservation behavior for 383 the treatment groups relative to the "building-level" baseline.

Table 3 and Fig. 2 confirm that students living in the treatment flats consumed more than the average level from within their respective buildings during the initial phase of the study. However, the identified gap significantly erodes overtime. Indeed, after approximately 2 months of disseminating information through emails, the average electricity consumption of treated flats is lower compared with others within their respective buildings, validating $H 1$. This means that, and as hypothesized, dissemination of individual and social information in a form of league table incites the competitive spirit in our subjects increasing their conservation efforts. The magnitude of this effect is consistent with previously cited field research and indicates the potential gains that could be derived by raising the visibility of energy usage via social comparisons. This reinforces the positive contribution that behavioral interventions could play in facilitating tangible adaptations in how people behave. While this trend is aligned to previous works conducted at the same 
Table 4 Linear regression model for the log weekly usage per student clustering by independent observations (teams)

\begin{tabular}{cll|l}
\cline { 2 - 3 } $\mathrm{t}: 2$ & & $(1)$ \\
\cline { 3 - 3 } $\mathrm{t}: 3$ & Variables & Log weekly usage per student \\
\cline { 3 - 4 } $\mathrm{t}: 4$ & No email stop & Ref \\
$\mathrm{n}: 5$ & Yes email stop & -0.00130 \\
$\mathrm{n}: 6$ & & $(0.154)$ \\
$\mathrm{t}: 7$ & Weeks & $-0.0264 * * *$ \\
$\mathrm{t}: 8$ & & $(0.00654)$ \\
$\mathrm{t}: 9$ & Constant & $2.970 * * *$ \\
$\mathrm{t}: 10$ & & $(0.0859)$ \\
$\mathrm{t}: 11$ & Observations & 294 \\
$\mathrm{t}: 12$ & Number of number of teams & 14 \\
$\mathrm{t}: 13$ & Robust standard errors in parentheses & \\
$\mathrm{t}: 14$ & $* * * p<0.01, * * p<0.05, * p<0.1$ &
\end{tabular}

397 university (Brock 2016), this is still something that could be highly prioritized in 398 future work to affirm the robustness of this result.

399 Although only a crude measure of persistence, the fall in efficiency between April 400 and May serves as an initial warning about how subjects respond to information over 401 time and how this relates to their behavior. Emails stopped in early May, and by the 402 end of the month, the average usage of energy among the treatment flats return to 403 above the building level (although not fully returning to the pre-intervention dispar404 ity). Two possible conjectures arise from this. The first is that good habits may erode 405 quickly once a nudge is no longer explicitly imposed upon individuals - this is 406 something that shall be considered further in the next subsection. The other is that by 407 the time students were exposed to many weeks of emails, the novelty or interest in 408 the project disappears. Both of these conjectures hold a strong policy relevance and 409 indicate that extreme care needs to be paid to the frequency, format, and timeline of 410 delivering such information in order to maximize and retain user engagement.

\section{${ }_{411}$ The Level of Persistence}

412 Figure 2 implies that there may be some questions regarding how long-lasting an 413 information stimulant may be. As shown in Table 1, we test this aspect by including 414 a subset of flats who stopped receiving emails after a period of just 6 weeks. 415 Nonetheless, these flats' readings were still taken for the full 22 weeks of the 416 study allowing their usage patterns to still be seen for a full 3 months after the 417 email termination date.

418 Table 4 confirms that no significant differences occurred between the two treat419 ment groups, which in principle gives us little support for $H 2$. However, upon closer inspection, it appears that this result may have been driven by the wide heterogeneity 


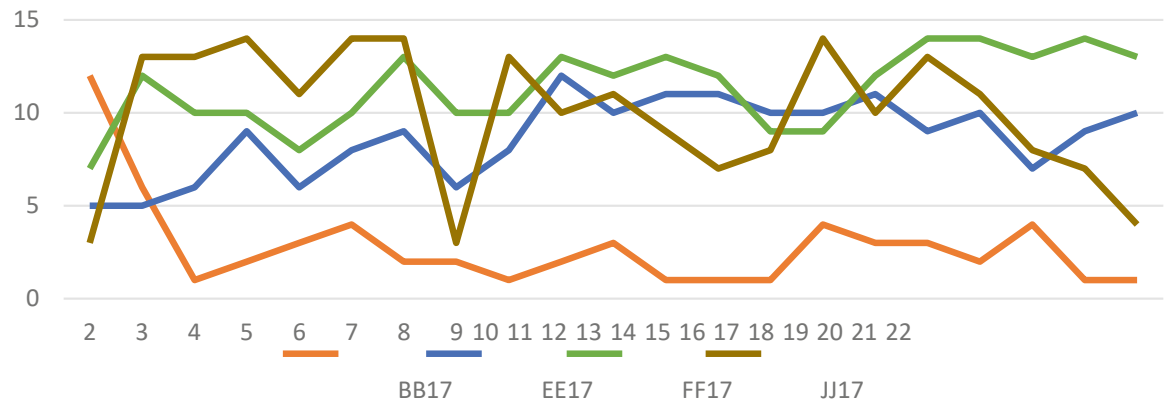

Fig. 3 The ranking trends of the four flats where emails stopped after 6 weeks

COMPARISON OF AVERAGE RANK TRENDS

12

10

8

6

4

2

0

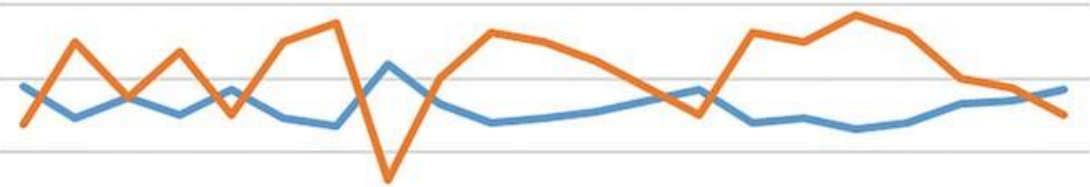

.

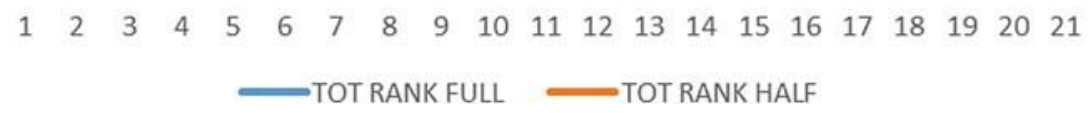

Fig. 4 Comparing ranking trends between those receiving emails for only 6 weeks against those receiving emails for the full study period

in the performances of the four "6-week" sub-treatment flats. Exemplified through Fig. 3, we see that Flat "BB17" was an extremely strong performer (hence low ranking) throughout the study period, perhaps because this group already acquired preexisting energy efficiency habits and constantly practices them. For both Figs. 4.2 and 4.3 , the crucial stage is Week 8 , which was the time emails stopped for the "6week" groups. With the exception of Flat "JJ17," Fig. 3 shows an apparent upward trend (and thus worsening rank) following this period. When aggregated in Fig. 4, this seems most pronounced in the initial weeks after the email stopped.

Furthermore, when inspecting Fig. 4, it is noteworthy to look at the slight increase in the rankings of those within the "full information" treatment after week 19. This is the time when the information disseminating emails stopped. The trends seen in weeks 9-11 for our '6-week subsample' and in weeks 19-21 for the remaining 
Table 5 Linear regression model for the log weekly usage per student clustering by independent observations (teams)

\begin{tabular}{cll|l}
\cline { 2 - 3 } $\mathrm{t}: 2$ & & $(1)$ \\
\cline { 3 - 3 } $\mathrm{t}: 3$ & Variables & Log weekly usage per student \\
\cline { 3 - 4 } $\mathrm{t}: 4$ & Non-prize & Ref \\
$\mathrm{n}: 5$ & Prize & 0.0888 \\
$\mathrm{n}: 6$ & & $(0.111)$ \\
$\mathrm{t}: 7$ & Weeks & $-0.0264 * * *$ \\
$\mathrm{t}: 8$ & & $(0.00654)$ \\
$\mathrm{t}: 9$ & Constant & $2.918^{* * *}$ \\
$\mathrm{t}: 10$ & & $(0.103)$ \\
$\mathrm{t}: 11$ & Observations & 294 \\
$\mathrm{t}: 12$ & Number of number of teams & 14 \\
$\mathrm{n}: 13$ & Robust standard errors in parentheses & \\
$\mathrm{t}: 14$ & $* * * p<0.01, * * p<0.05, * p<0.1$ &
\end{tabular}

433 groups imply that it is the immediate time period after stopping an information 434 interjection that creates the most severe reactions in behavior.

435 University accommodation contracts ceased from "week 22," which explains 436 why further monitoring did not occur. However, assessing these patterns in future 437 work could be easily achieved by simply bringing forward the treatment start date or 438 by using a set of subjects (e.g., postgraduate students or domestic residents) who live 439 in their accommodation for a full calendar cycle.

\section{${ }_{440}$ The Impact of Offering a Prize}

441 Another key aim is to see what impact (if any) extrinsic incentives have on the 442 subjects' decrease of their energy consumption. As previously stated, two strands of 443 competing literature exist here. The first argues that the added competition should 444 heighten the desire to improve one's standing, leading to an even greater reduction in 445 energy consumed. However, an opposing (theoretical and experimental) literature 446 shows evidence that extrinsic motivations can offset (or "crowd out") intrinsic 447 desires or motivation of pro-environmental behavior.

448 The results of this study are mixed. Table 5 observed no significant differences in 449 energy consumption. This result arises when formal econometric testing is used to 450 compare those in the "prize" versus "non-prize" treatment groups. This suggests that 451 the opportunity to reap additional extrinsic benefits through a strong relative perfor452 mance does not translate into greater instances of energy-saving behavior.

453 However, by delving a little deeper, a couple of interesting and policy-relevant 454 patterns emerge from those flats who were given the chance to win a prize.

455 The first of these results arises if we segment the results into three stages: before, 456 during, and after the intervention period. Table 6 provides the average consumption 
Table 6 A comparison of energy usage differences between prize and non-prize groups

\begin{tabular}{ll|l|l|l}
\hline & $\begin{array}{l}\text { Pre-intervention usage } \\
(\mathrm{KwH} / \text { week })\end{array}$ & $\begin{array}{l}\text { Intervention period usage } \\
(\mathrm{KwH} / \text { week })\end{array}$ & $\begin{array}{l}\text { Post-intervention usage } \\
(\mathrm{KwH} / \text { week })\end{array}$ \\
$\mathrm{t}: 2$ & $\begin{array}{l}\text { Prize } \\
\text { cohort }\end{array}$ & $14.99(5.59)$ & $16.85(6.96)$ & $14.22(4.21)$ \\
\hline $\begin{array}{l}\text { Non-prize } \\
\text { cohort }\end{array}$ & $12.1(3.76)$ & $16.92(6.89)$ & $14.03(5.68)$ \\
\hline
\end{tabular}

for the two groups across these periods. It shows us that within the "pre-intervention" phase, those in the "prize" treatment group consumed on average $23.9 \%$ more energy each week than those in the "non-prize" treatment. This means the "prize" subsample were relatively poor performers at the time the emailing began.

However, the gap not only shrunk but reversed through the intervention period wherein the "prize" treatment groups consumed a marginally lower level of energy on average per week than the remaining set of participants. The difference $(0.07 \mathrm{KwH})$ is marginal and statistically insignificant, but given the pre-intervention consumption levels, this implies that the potential for additional reward could represent some form of stimulus to respondents. This result validates our $\mathrm{H} 3 \mathrm{a}$. Indeed, as it was anticipated, the existence of an extrinsic motivation makes "prize" groups to make an extra effort in their electricity conservation. Regarding the post-intervention figures, we see the levels of energy usage from the "prize" groups almost return to their pre-intervention threshold. Yet the magnitude of this return is by no means as substantial as for the "non-prize" cohort, suggesting that perhaps there are some lasting effects from the extrinsic prize.

While this first effect seems promising, a second finding reveals that in the postintervention period, the average usage of the "Prize" subsample rose by $22 \%$ compared with the final week when emails were sent. Combined with statistics in Table 6, this implies that the "prize" flats exhibited a more pronounced downward trajectory in usage during the intervention period itself than "non-prize" counterparts. However, a rapid rise in the energy consumption was observed once prizes had been allocated, which validates our $H 3 b$. For individuals that are extremely competitive, this makes intuitive sense. Through the intervention period, they are likely to be very conscious of the amount of energy they were using, particularly in the weeks prior to the selection of the winning teams because of their strong desire to claim a prize. However, once the prizes were allocated, the strong impulse to be energy-efficient disappears, leading them to quickly reverting back to a pattern of 5 higher usage. It is noteworthy to highlight that this post-intervention pattern was not witnessed for flats within the "non-prize" treatment. This result is consistent with the "crowding-out" literature, which suggests that extrinsic incentives may work in the short term but might reduce the intrinsic motivation to perform the 9 pro-environmental action once the incentives are removed.

Informal evidence of this is given in Fig. 5. This illustrates the ranking of the leading "prize" flats over the duration of the study. Note that winners were determined by week 17 . The graph shows that the four leading flats in the prize treatment 


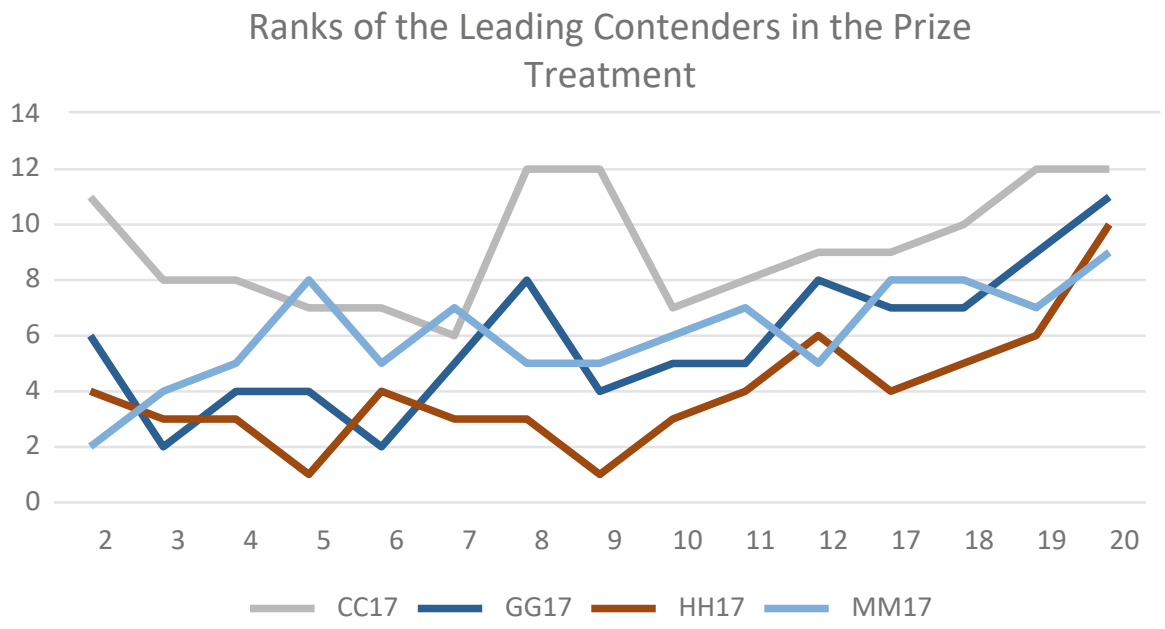

Fig. 5 Ranks of the leading contenders in the prize treatment

Table 7 A comparison of energy usage differences between Green and Non-Green Flats

\begin{tabular}{l|l|l|l}
\hline & $\begin{array}{l}\text { Pre-intervention usage } \\
(\mathrm{KwH} / \text { week })\end{array}$ & $\begin{array}{l}\text { Intervention period usage } \\
(\mathrm{KwH} / \text { week })\end{array}$ & $\begin{array}{l}\text { Post-intervention usage } \\
(\mathrm{KwH} / \mathrm{week})\end{array}$ \\
\hline $\begin{array}{l}\text { Green } \\
\text { Flats }\end{array}$ & $16.33(7.71)$ & $18.34(8.41)$ & $11.91(5.73)$ \\
\hline $\begin{array}{l}\text { Non- } \\
\text { Green } \\
\text { Flats }\end{array}$ & $12.73(3.38)$ & $16.42(6.36)$ & $15.65(4.55)$ \\
\hline
\end{tabular}

had maintained a steady rank throughout the intervention period but these quickly 498 consumption and stability of energy demand.

\section{${ }_{499}$ The Impact of Residing in a Green Flat} 505 and social information.

A really surprising result here is that "Green Flats" residents actually consume

One of the novel elements of this study is its ability to have a subset of the subject pool from a "Green Flat." Recall that these participants expressed a desire, far before the study begins, to live in an environmentally sustainable setting. It offers an opportunity to examine whether they have a lower level of energy usage and, of equal interest, whether they respond differently when are presented with individual more energy than those in standard residencies during the "pre-intervention" phase. 

513 ambitions.

514 Nevertheless, this trend of overconsumption disappears over the intervention 515 period and significantly reverses by the time the post-intervention period is reached. 516 These two results validate our $H 4 a$ and $H 4 b$. As we expected, these subjects react 517 positively to the information disseminated and maintain their good habits even after 518 the information is removed. Unfortunately, we have no way of disentangling 519 whether this occurs because of the information channels in themselves or instead 520 through a desire to defend a previously stated reputation. In any case, this finding is 521 intriguing, especially for one who is looking to design techniques that will get 522 consumers committing to longer-term pro-social activity. 531 disposition to embrace environmental attitudes.

\section{${ }_{532}$ Discussion} 538 and attitudes to sustainability on energy consumption.

539 It appears that the degree to which "good behavior" persists is highly dependent 549 predictable trends in energy demand. 

557 reveal disparate patterns of behavior.

Nevertheless, a significant heterogeneous response arises through this study, which suggests that policy-makers need to identify and seize opportunities to target information to the various population groups that share similar characteristics. This is something that the energy industry is already aware of through aforementioned studies in relation to performance (Abrahamse et al. 2005), political ideology (Costa 55 and Kahn 2013), and demographic status (Giulietti et al. 2005). However, this study explicitly demonstrates this, considering how both prizes and "green" individuals

\section{${ }_{558}$ Conclusion} 568 trends as a consequence.

569 The results imply that issuing ranking information can incite behavioral change. 577 removed. 578 While no evidence hints toward the crowding out effect of extrinsic motivations 584 removed.

This study builds upon a burgeoning literature that seeks to identify whether relatively cost-free behavioral nudging can influence people's energy consumption. To test this, students living in student residences at a UK university were provided with (absolute and relative) energy usage data through a weekly email. The study introduced new insights, firstly by issuing energy information at a flat (apartment) level and secondly by splitting this cohort to explore aspects relating to extrinsic motivation, persistent behavior, and preexisting environmental attitudes. This sought to assess (a) whether responses differ when data is provided through a group dynamic and (b) whether these imposed subtreatments create a range of consumption The treated flats involved in the study reduced their usage by a magnitude which make them jump from an above-average consumption to a below-average one relative to their building-level cohort. Interestingly, students in the "Green Flats" proved to be good performers through the intervention period. This result suggests that those students have a greater positive response to individual and comparative performance information with respect to non-"Green Flats" students. Importantly, this effect persists over time in the post-intervention even when the information is on intrinsic ones, there are serious questions regarding the long-term impact of offering such additional reward, particularly from the point after a promised incentive is issued. Finally, "good consumption habits" seem to erode quickly for those who receive the prize, and at multiple junctures in the study, an almost immediate upward trajectory in consumption is observed once emails ceased and information is economics. We advocate extending and expanding upon these experimental beginnings in order to strengthen the evidence for these early conjectures. The main implication is that policymakers, industries, and consumers alike must consider the role of nonfinancial stimuli in inciting small and yet significant changes to behavior. A motivation to change may exist, yet how long does this desire remains is highly debatable. Moreover, this project implies that the success of an intervention may 
592 crucially hinge on the way that it is imposed. This relates both to its frequency and its 593 target group's characteristics (i.e., demographic, socioeconomic, and psychological). 594 It suggests that an ability to nurture (or indeed even establish) a desire for behavioral 595 change in an environmental field such as energy usage will require a well-crafted and 596 thoroughly planned scheme if the anticipated benefits are to fully materialize.

597 Acknowledgments This study was supported by the University of East Anglia, School of 598 Economics and CBESS.

\section{${ }_{599}$ References}

600 Abrahamse W, Steg L, Vlek C, Rothengatter T (2005) A review of intervention studies aimed at 601 household energy conservation. J Environ Psychol 25(3):273-291

602 Alberts G, Gurguc Z, Koutroumpis P, Martin R, Muûls M, Napp T (2016) Competition and norms:

603 a self-defeating combination? Energy Policy 96:504-523

604 Alcott B (2005) Jevons' paradox. Ecol Econ 54(1):9-21

605 Allcott H (2011a) Consumers' perceptions and misperceptions of energy costs. Am Econ Rev

$606 \quad 101(3): 98-104$

607 Allcott H (2011b) Social norms and energy conservation. J Public Econ 95(9-10):1082-1095

608 Allcott H, Mullainathan S (2010) Behavior and energy policy. Science 327(5970):1204-1205

609 Allcott H, Rogers T (2014) The short-run and long-run effects of behavioral interventions:

610 experimental evidence from energy conservation. Am Econ Rev 104(10):3003-3037

611 Andreoni J (1990) Impure altruism and donations to public goods: a theory of warm-glow giving.

612 Econ J 100(401):464-477

613 Attari SZ, DeKay ML, Davidson CI, De Bruin WB (2010) Public perceptions of energy

614 consumption and savings. Proc Natl Acad Sci 107(37):16054-16059

615 Baik KH (2008) Contests with group-specific public-good prizes. Soc Choice Welf 30(1):103-117

616 Bault N, Coricelli G, Rustichini A (2008) Interdependent utilities: how social ranking affects choice 617 behavior. PLoS One 3(10):e3477

618 Bergstrom T, Blume L, Varian H (1986) On the private provision of public goods. J Public Econ 619 29(1):25-49

620 Brock M (2016) Is the Monster Green-Eyed, or just Green? Assessing the impact of group cohesion 621 and environmental attitudes on energy conservation habits (working paper)

622 Cason TN, Masters WA, Sheremeta RM (2010) Entry into winner-take-all and proportional-prize 623 contests: an experimental study. J Public Econ 94(9-10):604-611

624 Cerasoli CP, Nicklin JM, Ford MT (2014) Intrinsic motivation and extrinsic incentives jointly

625 predict performance: a 40-year meta-analysis. Psychol Bull 140(4):980

626 Clark DJ, Riis C (1998) Competition over more than one prize. Am Econ Rev 88(1):276-289

627 Convery F, McDonnell S, Ferreira S (2007) The most popular tax in Europe? Lessons from the Irish 628 plastic bags levy. Environ Resour Econ 38(1):1-11

629 Costa DL, Kahn ME (2013) Energy conservation "nudges" and environmentalist ideology: 630 evidence from a randomized residential electricity field experiment. J Eur Econ Assoc 631 11(3):680-702

632 Croson R, Treich N (2014) Behavioral environmental economics: promises and challenges. Environ 633 Resour Econ 58(3):335-351

634 Czajkowski M, Hanley N, Nyborg K (2014) Social norms, morals and self-interest as determinants 635 of pro-environment behaviours. Working paper 2014-03, Department of Geography and 636 Sustainable Development, University of St Andrews. Available through http://www.stir.ac.uk/ 637 management/research/economics/working-papers/. Working paper 2014-06 
638 Dasgupta P, Southerton D, Ulph A, Ulph D (2016) Consumer behaviour with environmental and 639 social externalities: implications for analysis and policy. Environ Resour Econ 65(1):191-226 640 Davis DD, Reilly RJ (1998) Do too many cooks always spoil the stew? An experimental analysis of 641 rent-seeking and the role of a strategic buyer. Public Choice 95(1-2):89-115

642 Delmas MA, Lessem N (2014) Saving power to conserve your reputation? The effectiveness of 643 private versus public information. J Environ Econ Manag 67(3):353-370 644 Department for Energy and Climate (DECC), Cabinet Office (2015) Energy Consumption in the $645 \quad$ UK. https://www.gov.uk/government/uploads/system. Accessed 15 July 2016

646 Diener E, Biswas-Diener R (2011) Happiness: unlocking the mysteries of psychological wealth. $647 \quad$ Wiley, New York

648 Dolan P, Metcalfe R (2013) Neighbors, knowledge, and nuggets: two natural field experiments on 649 the role of incentives on energy conservation. CEP discussion papers, CEPDP1222. Centre for 650 Economic Performance, London School of Economics and Political Science, London 651 Doraszelski U, Markovich S (2007) Advertising dynamics and competitive advantage. RAND $652 \quad$ J Econ 38(3):557-592

653 Druckman JN, Kam C D (2009) Students as experimental participants: a defense of the 'narrow data 654 base'. SSRN eLibrary

655 Fehr E, Schmidt KM (1999) A theory of fairness, competition, and cooperation. Q J Econ

$656 \quad 114(3): 817-868$

657 Frank SA (2003) Repression of competition and the evolution of cooperation. Evolution 658 57(4):693-705

659 Giuliano P, Spilimbergo A (2009) Growing up in a recession: beliefs and the macroeconomy 660 (no. w15321). National Bureau of Economic Research, Cambridge, MA

661 Giulietti M, Price CW, Waterson M (2005) Consumer choice and competition policy: a study of UK 662 energy markets. Econ J 115(506):949-968

663 Hargreaves T, Nye M, Burgess J (2013) Keeping energy visible? Exploring how 664 householders interact with feedback from smart energy monitors in the longer term. Energy

665 Policy 52:126-134

666 HM Government (2006) UK Climate Change Programme 2006. The Stationery Office, London 667 Information on the SMART Meter rollout in the UK in 2020. https://www.smartenergygb.org/en/ 668 smart-future/about-the-rollout. Accessed 05 Jan 2018

669 Kahneman D, Knetsch JL (1992) Valuing public goods: the purchase of moral satisfaction.

670 J Environ Econ Manag 22(1):57-70

671 Kallbekken S, Sælen H (2013) 'Nudging' hotel guests to reduce food waste as a win-win

672 environmental measure. Econ Lett 119(3):325-327

673 Konrad KA (2009) Strategy and dynamics in contests. OUP Catalogue, Oxford

674 Kotchen MJ (2009) Voluntary provision of public goods for bads: a theory of environmental offsets. 675 Econ J 119(537):883-899

676 Lugovskyy V, Puzzello D, Tucker S (2010) An experimental investigation of overdissipation in the 677 all pay auction. Eur Econ Rev 54(8):974-997

678 Nitzan S, Ueda K (2009) Collective contests for commons and club goods. J Public Econ 679 93(1-2):48-55

680 Olson MJ (1965) The logic of collective action: public goods and the theory of groups. Harvard $681 \quad$ University Press, Cambridge

682 Pellerano JA, Price MK, Puller SL, Sánchez GE (2017) Do extrinsic incentives undermine social 683 norms? Evidence from a field experiment in energy conservation. Environ Resour Econ 684 67(3):413-428

685 Putnam R, Alone B (1995) America's declining social capital. J Democr 6:65

686 Steg L, Lindenberg S, Keizer K (2016) Intrinsic motivation, norms and environmental behaviour: 687 the dynamics of overarching goals. Int Rev Environ Resour Econ 9(1-2):179-207

688 Sugden R (1984) Reciprocity: the supply of public goods through voluntary contributions. Econ J 689 94(376):772-787 
690 Terry DJ, Hogg MA, White KM (1999) The theory of planned behaviour: self-identity, social 691 identity and group norms. Br J Soc Psychol 38(3):225-244

692 Thaler RH, Sunstein CR (2009) Nudge: improving decisions about health, wealth, and happiness.

693 Penguin

694 Urdiales MP, Lansink AO, Wall A (2016) Eco-efficiency among dairy farmers: the importance of 695 socio-economic characteristics and farmer attitudes. Environ Resour Econ 64(4):559-574

696 Weimann J (1994) Individual behaviour in a free riding experiment. J Public Econ 54(2):185-200 
Index Terms:

Behavioural nudging 2

Behavioural predictions 11-12

Environmental economics 5

Environmental nudging 4-7

Extrinsic motivations 6, 8, 17-18

Field experiment 5-6

Green flats project 6-8

Persistence 11

Social information 3, 11, 13

Sustainability $7-8$, 